\title{
1 Accuracy, limitations and cost-efficiency of zeDNA-based community survey in tropical frogs
}

3

4 Miklós Bálint ${ }^{1,2}$, Carsten Nowak ${ }^{1,2}$, Orsolya Márton ${ }^{1,3}$, Steffen U. Pauls ${ }^{1,2}$, Claudia

5Wittwer ${ }^{1}$, Jose Luis Aramayo B. ${ }^{4}$, Arne Schulze $^{5}$, Thierry Chambert ${ }^{6}$, Berardino Cocchiararo ${ }^{1,2}$, 6Martin Jansen ${ }^{1}$

7

8 'Senckenberg Research Institute and Natural History Museum Frankfurt, 9Senckenberganlage 25, 60325 Frankfurt, Germany

10 2LOEWE Centre for Translational Biodiversity Genomics (LOEWE-TBG), 11Senckenberganlage 25, 60325 Frankfurt, Germany

$12{ }^{3}$ Institute for Soil Sciences and Agricultural Chemistry, Centre for Agricultural Research, 13Hungarian Academy of Sciences, Herman Otto str. 15, H-1022 Budapest, Hungary

$14 \quad{ }^{4}$ Museo Historia Natural Noel Kempff Mercado (Universidad Autónoma Gabriel Rene 15Moreno), Av. Irala 565, Santa Cruz de la Sierra, Bolivia

17Germany 


\section{Abstract}

21Rapid environmental change in highly biodiverse tropical regions demands efficient

22biomonitoring programs. While existing metrics of species diversity and community composition 23rely on encounter-based survey data, eDNA recently emerged as alternative approach. Costs 24and ecological value of eDNA-based methods have rarely been evaluated in tropical regions, 25 where high species richness is accompanied by high functional diversity (e.g. the use of 26different microhabitats by different species and life-stages). We first tested whether estimation 27of tropical frogs' community structure derived from eDNA data is compatible with expert field 28assessments. Next we evaluated whether eDNA is a financially viable solution for biodiversity 29monitoring in tropical regions. We applied eDNA metabarcoding to investigate frog species 30 occurrence in five ponds in the Chiquitano dry forest region in Bolivia and compared our data 31 with a simultaneous visual and audio encounter survey (VAES). We found that taxon lists and 32community structure generated with eDNA and VAES correspond closely, and most deviations 33are attributable to different species' life histories. Cost efficiency of eDNA surveys was mostly 34influenced by the richness of local fauna and the number of surveyed sites: VAES may be less 35 costly in low-diversity regions, but eDNA quickly becomes more cost-efficient in high-diversity 36regions with many sites sampled. The results highlight that eDNA is suitable for large-scale 37biodiversity surveys in high-diversity areas if life history is considered, and certain precautions in 38sampling, genetic analyses and data interpretation are taken. We anticipate that spatially 39extensive, standardized eDNA biodiversity surveys will quickly emerge in the future.

\section{$40 \quad$ Keywords}

41 Amphibians, metabarcoding, tropical biodiversity, conservation, community ecology, cost 42comparison 


\section{$43 \quad$ Introduction}

$44 \quad$ Improvements on most biodiversity loss indicators lag behind the 20 "Aichi Biodiversity

45Targets" (UNEP 2016) that aim to reduce the decline of biodiversity by 2020 (Tittensor et al.

462014). An important component of the biodiversity crisis is the extinction of species. Based on

47current trends in mammals, birds, reptiles and amphibians, it has been projected that the

48biodiversity crisis may lead to the 6th Mass Extinction over the next three centuries if all

49threatened species go extinct (Barnosky et al. 2011). Current rates of extinction may even be

50 much higher if one considers the extinction that likely occurred during the last few decades-

51centuries, but went unnoticed because the now-extinct species had small ranges, were never

52described or only described on the eve of their extinction (Pimm et al. 2014; Lees \& Pimm

532015). It is however difficult to assess which species are endangered and to what extent. First,

54most taxa remain poorly described: in some highly diverse regions many species will likely go

55extinct before they are discovered (Costello et al. 2013; Lees \& Pimm 2015). Second, cryptic

56genetic diversity is common within morphospecies (Pfenninger \& Schwenk 2007; Pauls et al.

572013), and global change may impact cryptic diversity more severely than morphospecies

58(Bálint et al. 2011). Third, data on population-level trends is scarce, even for well-known species

59(Butchart et al. 2010). Better population-level biodiversity data is thus urgently needed to 1)

60understand biodiversity patterns and extinction threats, 2) improve forecasting abilities about

61 future biodiversity, and 3) improve humanity's responses to the challenges of biodiversity loss.

62This data is crucial in times when conservation action is increasingly demanded by society

63(Tittensor et al. 2014).

64 The importance of internationally coordinated, standardized biodiversity data collection is 65long recognized both in science and in conservation (Henry et al. 2008). This is particularly true $66 f o r$ the most biodiverse areas. The tropics are generally underrepresented in ecological studies 
67(Clarke et al. 2017; Stroud \& Feeley 2017). In addition, encounter-based data collection is 68logistically challenging since it needs considerable funds to bring enough specialists for different 69organismic groups to remote areas, thus insufficient funds and expertise often limit 70comprehensive surveys. Indirect species records through environmental DNA are increasingly 71heralded as an alternative to encounter-based surveys (Thomsen \& Willerslev 2015; Pedersen 72et al. 2015). eDNA also facilitates the standardization of biodiversity surveys at both regional 73and global scales since community composition data can be obtained by high-throughput74sequencing of standardized, taxonomically informative marker genes (metabarcoding) (Taberlet 75et al. 2012a; Cristescu 2014). Aquatic or semiaquatic vertebrates such as frogs and other 76amphibians or fish have been early targets of eDNA based studies, either focusing on the 77detection of single species (e.g. Ficetola et al. 2008; Goldberg et al. 2011; Jerde et al. 2011; 78Thomsen et al. 2012a) or entire communities (e.g. Thomsen et al. 2012b; Valentini et al. 2016; 79Shaw et al. 2016; Yamamoto et al. 2017). The use of next-generation sequencing approaches 80led to a boost in data acquisition (Taberlet et al. 2012b) and is considered to make important 81contributions to biodiversity research (Rees et al. 2014; Bohmann et al. 2014). eDNA-based 82metabarcoding may present one of several tools needed to globally coordinate initiatives for 83ecosystem monitoring and sustainable management (Bush et al. 2017; Schmeller et al. 2017).

84 In this study we evaluate whether eDNA metabarcoding is suitable for inventories of 85frogs, a group with particular high species-diversity in tropical regions. Frogs and other 86amphibians are sentinel victims of the biodiversity crisis: more than one-third of the 87approximately 7500 described species are endangered (Stuart et al. 2004; Bishop et al. 2012; 88Whittaker et al. 2013). Frogs are also known for being a highly diverse, but incompletely 89described taxon, especially in the tropics (Ferrão et al. 2016; Caminer et al. 2017). Many 90“widespread” morphospecies harbor considerable cryptic genetic diversity and are better 91considered complexes of closely related species with much smaller ranges (Fouquet et al. 2007; 
92Gehara et al. 2013, 2014; Ortega-Andrade et al. 2015). Efficient implementation of amphibian 93conservation measures (e.g. the prioritization of areas for conservation, or informing society and 94stakeholders about conservation needs) are only possible with geographically broad-scaled 95fine-grain, taxonomically well-resolved faunistic data, but our current understanding of present 96and future amphibian biodiversity is often based on rare, spatially and temporally scattered 97observations of phenotypically defined taxa.

98 First efforts have been made to test the suitability of eDNA for the survey of tropical frog 99biodiversity (Lopes et al. 2016), but important practical aspects remain unaddressed. First, it is 100 not clear which fraction of the local species pool is represented by amphibian eDNA in tropical 101water bodies. Existing comparisons of encounter-based surveys and eDNA either do not include 102non-adult life stages, or they use already compiled fauna lists for the evaluation of eDNA 103performance without consideration of life history traits or behavioral aspects at the moment of 104sampling. However, temporal and spatial patterns of microhabitat use by frogs is largely 105species-specific and influenced by phenology and reproduction modes (e.g. Duellmann \& Pyles 1061983, Haddad \& Prado 2005, Wells 2010), which can induce strong biases in biodiversity data 107(Petitot et al. 2014). Second, the degree to which aquatic eDNA can provide accurate 108assessments of community structure remains largely unevaluated. Most studies to date have 109only investigated the correspondence between encounter-based and metabarcoded taxon lists 110(Miya et al. 2015; Valentini et al. 2016), although community structure assessments themselves 111may be of higher importance for many applications (Ji et al. 2013; Elbrecht et al. 2017). Third, it 112is not clear whether, and under what conditions eDNA is financially efficient since comparisons 113are lacking (Lopes et al. 2016), although these comparisons are essential for deciding on data 114collection strategies.

115 Here we address whether 1) detectability of tropical amphibians with eDNA is linked to 116species' life history, and 2) eDNA sampling provides accurate data for the characterization of 
bioRxiv preprint doi: https://doi.org/10.1101/176065; this version posted July 13, 2018. The copyright holder for this preprint (which was not certified by peer review) is the author/funder, who has granted bioRxiv a license to display the preprint in perpetuity. It is made available under aCC-BY-ND 4.0 International license.

117community assembly. Finally, we present a framework for cost comparisons between

118encounter- and eDNA-based biodiversity survey that may be adapted to other systems beyond

119amphibians. We compare the results of long- and short-term encounter-based field surveys, and 120an eDNA survey of tropical amphibians in a well-characterized high-diversity area in Bolivia. 


\section{$123 \quad$ Materials and methods}

124 The study area is located the Chiquitano region of Bolivia, a forest-savanna ecotone 125between Amazon, Cerrado and Gran Chaco in a transition zone among humid and dry forests 126that are special in regard to their taxonomic and functional diversity (Castro et al. 1999). The 127region contains the largest intact, old-growth block of seasonally dry tropical forests in South 128America (Miles et al. 2006; Power et al. 2016). Samples were collected from ponds in the 129vicinity of the Biological Station "Centro de Investigaciones Ecológicas Chiquitos" on the San 130Sebastián cattle ranch (S16.3622, W62.00225, $500 \mathrm{~m}$ a.s.I.), $24 \mathrm{~km}$ south of the town of 131Concepción, Province of Ñuflo de Chávez, Santa Cruz Department, Bolivia. A description of the 132area is given by Schulze et al. (2009). This area is well characterized with respect to 133amphibians, including both larvae and adults (Schulze et al. 2015). Intensive long-term 134assessments have resulted in the detection of 45 frog species in the area (e.g. Jansen 2009; 135Schulze et al. 2009, 2015; Jansen et al. 2011), as well as the discovery of cryptic intraspecific 136diversity (e.g. Jansen et al. 2011; Jansen et al. 2016).

138also section "Site and ponds" in the Supplemental information). At these ponds, 35 species 139have been recorded in previous long-term surveys. Water samples were obtained from three 140sampling points at each pond (Fig. 1): These water samples consisted of four liters of water 141 collected into two two-liter silicon bottles. One sample of $2 \times 2$ liters was taken at each sampling 142point of ponds T1 - T4. Three samples of $2 \times 2$ liters were taken on each sampling points of 143pond T5 to check for sampling variation, i.e. whether replication in the sampling records more 144variation in community composition compared to replication in PCR steps. We also sampled and 145filtered water from two field controls: Tap water from the station from a covered well, and water 
146from an aquarium with tadpoles of Leptodactylus vastus at the station. The water samples were 147 filtered at the station immediately after collection.

148 Samples were filtrated with a vacuum filtration unit (Duran Group, Wertheim, Germany), 149which was connected to a vacuum membrane pump (Laboport, both Carl Roth GmbH + Co. KG, 150Karlsruhe, Germany). Filtration was performed until complete clogging of the filters. For each 151sample, the water from the two bottles was filtered separately on two glass-fiber filters (GFF, 152pore size $2 \mu \mathrm{m})$. One of the filters was preserved in CTAB (A), the other filter was dried 153immediately (B). Our intention here was to evaluate if filter preservation influences species 154detection, since the transportation of dry filters may be considerably simpler compared to wet 155filters. The flow-through from the two GFF filtrations was combined and filtered with a nylon filter 156until clogging (NF, pore size $0.2 \mu \mathrm{m}$, Millipore, Merck, Darmstadt, Germany). This filter was 157immediately dried after filtration (C). We intended to evaluate if the larger pore-size filters 158sufficiently capture anuran eDNA, or finer pore filters allow for additional species detection. To 159avoid cross-contamination we changed gloves with every new sample and disinfected hands 160 with ethanol (96\%), as well we cleaned filtration unit with ethanol (96\%) after each pond or site. Combined visual and audio encounter surveys (VAES, Zimmerman 1994), and a tadpole 162survey (TS, Schulze et al. 2015) were conducted by experienced observers (MJ and AS) to 163generate a presence/absence matrix of species for each pond. Frogs surveys were performed 164at night (between 21:00 and 00:30 hours) during 0.5 - 1 hrs transect walks along the ponds to 165 detect and identify specimens in vegetation, in water and on the ground around ponds. 166Detections occurred from either visual (using flashlights and headlamps) or auditory species 167identification. Tadpoles were sampled with dip nets once during daytime and once at night in 168each pond as well as the riparian vegetation. 
170handling of environmental DNA samples. Several working routines have been implemented in 171the laboratory to avoid contamination of samples and reactions, including spatial separation 172from the other DNA facilities (separate room), strict decontamination protocols using UV light 173and bleach, physical separation of extraction and PCR work spaces, automated extraction, and 174restricted access to staff trained in the handling and analysis of forensic and environmental 175 samples.

177extraction method according to Strand et al. (2014) and Wittwer et al. (2017). Dried nylon filters 178(C) were extracted with DNeasy Blood \& Tissue Kit (Qiagen, Hilden, Germany) following 179Thomsen et al. (2012b). Negative controls were included in all extraction sessions (see also 180DNA extraction in the Supplemental information). The barcode amplification targeted 181mitochondrial 16S ribosomal DNA. We designed primers (see Primer design in Supplemental 182information for details on design and primer tests) for a $150 \mathrm{bp}$ fragment with the reference 183database of local species (sequences from 159 specimens, Jansen et al. 2011; Schulze et al. 1842015). The primers were tested on a subset of 12 species. PCRs were run on 96-well plates in $18515-\mu l$ reaction volumes with a touchdown protocol, with four technical PCR replicates per 186sample (see PCR setup in the Supplemental information for PCR protocol and cycling 187conditions). We included four negative PCR controls (ultra-sterile water), four extraction blanks, 188and two positive controls on each plate. Positive controls consisted of 1) equimolar positives 189where DNA of the twelve frog species (primer development) was pooled in equimolar 190concentration (5 ng/ $\mu \mathrm{l})$, and 2) non-equimolar positives where a concentration series was used 191 by diluting the $5 \mathrm{ng} / \mu \mathrm{l}$ templates $1 \mathrm{x}$ to $512 \mathrm{x}$ dilution. PCR replicates were individually labeled 192with multiplexing indices designed by Kozarewa and Turner (2011). PCR products were purified 193with Agencourt AMPure XP SPRI magnetic beads (Beckman Coulter, Brea, CA), pooled in 
194equal volumes, and paired-end-sequenced ( $2 \times 150$ bp) on an Illumina NextSeq 500 sequencer 195at StarSEQ GmbH (Mainz, Germany).

196 The bioinformatic pipeline for sequence processing mostly relied on OBITools v1.2.0 197(Boyer et al. 2016, see Sequence processing in the Supplemental information for details). We 198performed two reference-based taxonomic assignments, first with a custom database of $16 \mathrm{~S}$ 199sequences of 159 specimens from the regional amphibian fauna (16S_custom), and second 200 with all 16 S sequences found in the EMBL (release 125, 16S_EMBL). Further filtering was done 201in R (R Core Team 2017) with a script supplied on GitHub:

202https://github.com/MikiBalint/amphibian-eDNA. This includes an ordination of all PCR replicates, 203negative and positive controls. This ordination was used to identify outlier replicates of samples 204from different ponds (Supplemental Fig. S1).

205 We followed recommendations for the statistical analyses of marker gene community 206data (Bálint et al. 2016). eDNA faunistic differences among the five ponds were visualized with a 207latent variable model-based ordination in R ('boral', Hui et al. 2015), and tested with 208multispecies generalized linear models (GLMs in 'mvabund', Wang et al. 2012). We used read 209abundances as input data for the boral ordination and the multispecies GLMs since presence210absences inferred from read abundances may overestimate the importance of rare sequence 211variants on community structure (Bálint et al. 2016). Different filtrates were included as distinct 212samples into the analyses since we wanted to see the variation among closely related samples 213(e.g. the three filtrates taken at the same point of a pond) versus the variation among distinct 214samples (e.g. originating from different ponds). We assumed a negative binomial distribution for 215both boral and mvabund analyses since read abundances are overdispersed counts, with a 216strong uniform prior on the dispersion parameter in boral (0-3). The surveyed ponds were 217markedly different in size, vegetation, water depth, etc, thus we considered pond identity as a 218 good predictor of community composition. The pond effect was evaluated with analysis of 
219variance (likelihood-ratio test, PIT-trap resampling, 1000 bootstrap replicates). We performed a 220model-based ordination also for the VAES presence/absence data (since no abundance data 221 was collected during the VAES), and then used a Procrustean superimposition (Peres-Neto \& 222Jackson 2001) to evaluate how the VAES-based ordination of ponds matches the ordination of 223centroids of eDNA samples. We compared the efficiency of filter preservation (CTAB or dried) 224on the successful detection of species with a site occupancy model (MacKenzie et al. 2002; 225Bailey et al. 2014), implemented in the R package 'unmarked' (Fiske et al. 2011). We used the 226single season false-positive occupancy model developed by Miller et al. (2011, for details see 227Site occupancy models in Supplemental information).

228 For cost comparisons, we considered a typical eDNA survey scenario: samples are 229 collected in the field and later processed in a dedicated laboratory. For the encounter-based 230survey we considered a scenario with a similar separation of the fieldwork and species 231identification: species records (audio or visual) are collected by a field biologist, and later 232identified or verified by an expert in the office/laboratory. The parameters in our cost models are 233an approximation of the variables involved in the present study and involve a learning effect in 234the efficiency of the taxonomic expert (see Cost comparison in the Supplemental information for 235details). The sampling and identification costs of VAES are dependent both on the number of 236sampling sites, and the number of species since each species needs to be recorded. During the 237eDNA survey samples are collected by a field biologist, analyzed in a lab and sequenced by an 238external provider. The costs of eDNA sampling and identification depend on the number of sites, 239but not on the number of species. We kept some cost factors constant: the costs for training the 240frog taxonomic expert and the VAES observers, the costs for building up the eDNA 241metabarcoding facilities (clean rooms and equipment to perform DNA manipulations, except 242sequencing), and the databases necessary for the sequence assignment. We assume that 243travel costs are the same for the two survey types, and that the time necessary to walk between 
bioRxiv preprint doi: https://doi.org/10.1101/176065; this version posted July 13, 2018. The copyright holder for this preprint (which was not certified by peer review) is the author/funder, who has granted bioRxiv a license to display the preprint in perpetuity. It is made available under aCC-BY-ND 4.0 International license.

244frog observations and eDNA sampling points is the same. All model parameters and 245calculations are accessible on FigShare (Bálint et al. 2017). 


\section{$246 \quad$ Results}

247 The sequencing resulted in 12742273 read pairs (deposited in ENA as PRJEB22113), 248of which 9479299 were identified as complete 16S amplicons. De-replication of the reads (see 249Supplemental Information: Sequence processing for more information on the steps) resulted in 250631003 unique sequences variants. Only 22706 of these variants were represented by at least 25110 reads and retained for further processing. The sequence cleanup resulted in 14442 high 252quality sequence variants, 13497 coming from the present experiment. Of these, 4805 253sequence variants were taxonomically assigned by the ecotag command with the 16S_custom 254database, and 8692 with the 16S_EMBL database. The ecotag outputs are accessible on 255FigShare (https://doi.org/10.6084/m9.figshare.5099842.v5), and can be combined and simplified 256with the R script provided on GitHub (https://github.com/MikiBalint/amphibian-eDNA). The 257assigned sequence variants represented 8011631 sequences. After bionformatic processing 258with OBITools 561 of these sequence variants were identified as 'head' sequences, i.e. 259sequences that have no variants more abundant than a predefined percentage of their own 260 count, here $5 \%$ (see also Sequence processing in the Supplemental information) in at least one 261sample (6 965866 reads). The original read numbers were re-assigned to these head sequence 262variants, and the read numbers were used in downstream analyses. Several of these 561 head 263sequence variants were found also in the negative controls. After removing the reads assigned 264to these, the final sample - sequence variant abundance matrix contained 5815014 265sequences. These belonged to several groups: frogs (2 158 534), fish (1 692 613), insects (304 266059), mammals (14 006), birds (967), and bacteria and other groups (1 063 156).

268of the eDNA samples (see species_abundance_matrix.csv - zipped - on FigShare:

269https://figshare.com/articles/_/5099842). Numbers of frog species detected by both methods, 
270eDNA and VAES, varied between 3 and 18 per pond (Table1). Several of the species present 271at the ponds had no aquatic life phase during the time of survey (i.e. no larvae or adults in the 272 water), and this likely resulted in lack of detection. To better evaluate the performance of the 273eDNA approach we thus assembled "reduced" VAES data sets containing only those species 274that are known to have an aquatic life phase during the survey period. For example, we 275excluded Leptodactylus fuscus, a species that was observed calling from the shore of the pond 276during the survey, but for which no tadpoles were recorded at that time.

278 In summary, in the five ponds 31 frog species were detected in total with both VAES and 279eDNA. Each of these methods detected 25 species, while the TS detected 4 species; 19 280species were detected by both eDNA survey and VAES (Fig. 2A; Table 1). Six species were 281 detected only by eDNA, and six species were detected only by VAES. If we consider only 282species with aquatic life phase during the sampling ("reduced" VAES data set; $N=20$ for all 283ponds), of these eDNA detected 19 (Fig. 2B, Table 1, Supplemental Table S1).

284 We detected 11 species (of the twelve) from the equimolar DNA concentration positive 285controls, and 6 in the non-equimolar DNA concentration controls (Supplemental Fig. S2). Read 286numbers in the equimolar PCR controls were highly variable, but strongly correlated among the 287controls ( $R>0.7$ for each pair of positive controls, Supplemental Fig. S2A). The read numbers 288in the non-equimolar positive control were strongly linked to the DNA template concentrations of 289the PCRs (Pearson correlation coefficient $R=0.97$, Supplemental Fig. S2B). Only 290Leptodactylus vastus was recovered in the field positive control (water from an aquarium with $L$. 291 vastus tadpoles).

292 We found no difference in detection probability between the filter preservation methods 293(CTAB buffer - A: detection probability $p_{1}=0.278[0.242 ; 0.317]$; dry - $B: p_{1}=0.243[0.209 ; 0.281]$ ), 
294Supplemental Fig. S3). Interestingly, subsequent filtering of water filtered through glass fiber 295filters with a $0.2 \mu \mathrm{m}$ nylon filter - C, appeared to show an increased detection probability $296\left(p_{1}=0.327,95 \%\right.$ C.I. $=[0.285 ; 0.372]$. The three approaches were equivalent with respect to 297false positive probabilities (Supplemental Fig. S3).

298 Regarding the community structure assessment based on the eDNA data, replicate 299samples of each pond grouped relatively tightly on the latent variable model ordination (Fig. 3A). 300The pond identity was a statistically significant predictor of frog communities in the five ponds $301($ ANOVA $, d f=6, d e v=534.99, p<0.01)$. This is reflected in the $95 \%$ confidence intervals of the 302group centroids on the ordination which clearly separates all ponds except T1 and T3 (Fig. 3A). 303The ordination of the eDNA pond centroids closely corresponds with the ordination of 304observations from the five ponds with VAES (Procrustes permutation test, $R=0.8, p=0.03$, Fig. 3053B).

306 The cost model of VAES and eDNA showed that the starting costs (i.e. with few 307sampling sites) for VAES are relatively low, but these costs rapidly increase until the taxonomic 308expert becomes familiar with the regional frog fauna (Fig. 4). The VAES price is dependent on 309the species richness: first, the VAES observer needs to record each species on the field, and 310then the taxonomic expert needs to listen to each recording (Fig. 4). eDNA metabarcoding has a 311relatively high entry price since consumables and sequencing are costly, regardless of the 312number of sites. eDNA survey prices are then a linear function of the number of sampling sites, 313and an increase in the site numbers simply adds to sampling and consumable costs, but does 314 not influence neither the time spent in the laboratory, nor the sequencing costs (Fig. 4). 


\section{$316 \quad$ Discussion}

317 The one-time eDNA survey detected 25 species in the studied ponds and confirmed the 318presence of (i) almost all species that were in contact with water during the survey time, (ii) all 319species that had tadpoles in the ponds, (iii) more than half of all 45 species ever recorded from 320 the area, and (iv) about $65 \%$ of the 35 species ever recorded in the five surveyed ponds. The $321 \mathrm{eDNA}$ dataset recorded clear differences among the frog communities in the surveyed ponds, a 322result also in accordance with the VAES data. The comparison of VAES and eDNA cost models 323show that eDNA biodiversity surveys may be a cost-efficient alternative to VAES in species-rich 324areas, but not necessarily in areas with low species numbers. Specific recommendations and 325technical remarks are presented in the Supplemental information. eDNA approaches for routine use in tropical regions will benefit from the implementation 327 of straightforward and robust sampling techniques. The comparison of the filtration-preservation 328approaches shows that filters can be dried in the field before being sent to a lab. Currently only 329few comparative studies exist regarding the preservation of eDNA filtrates on filters (e.g., Hinlo 330et al., 2017; Spens et al., 2017). Hinlo et al. (2017) showed that the simple refrigeration of filters 331 may be preferred to frozen storage. Here we show that filters can be dried in the field: this 332simplifies transportation and storage since no special precautions are needed, unlike for liquid 333handling. Interestingly, small pore-size nylon filters seemed to recover a high proportion of 334target DNA that had previously passed through a $2 \mu \mathrm{m}$ mesh sized glass fibre filter. While this 335result may be caused by the different extraction methods used, we consider it likely that a large 336proportion of DNA occurred in extracellular form. This result suggests that alternative filtering 337methods based on fine-scale mesh sized filtration with limited filtering volumes may further 338increase success rates in eDNA studies on amphibian communities. By limited volumes we do 339not suggest sampling only a few hundred $\mathrm{ml}$ of water, but rather to sample enough from a 
340 waterbody to ensure representativeness, and then filter from this well-mixed sample until the 341 filter clogs.

342 During the one-time surveys, six species were only detected with eDNA, and not with 343VAES (Fig. 2A). Four of these species (Dermatonotus muelleri, Leptodactylus elenae, 344Osteocephalus taurinus, Rhinella schneideri) are quite common in the area. The detection of 345these four species by eDNA but not by VAES may result from the low abundance of adults or 346tadpoles in the ponds, or a lack in acoustic activity. In some cases eDNA detections are even 347likely based on single tadpoles or single adults only. For example, one adult L. syphax was 348heard calling from a crevice of a rocky outcrop, its usual habitat (de Sá et al. 2014), 349approximately 30 m away from T2, but detection by eDNA most probably was due to the 350presence of tadpoles in pond T2. All other species that had tadpoles in the ponds were also 351detected by eDNA (Table 1). Furthermore, our results suggest that detection of rare or solitary 352species by eDNA is possible, since the presence of $L$. vastus in the eDNA most possibly can be 353traced back to single, territorial adult males that were present during VAES of T4 and T5. These 354examples show the great potential of eDNA for detection of elusive life stages like tadpoles and 355less abundant species. The remaining two species detected only with eDNA are not known to $3560 c c u r$ in the area, thus they are candidates for false assignments. The low read numbers 357assigned to these species also supports this (Supplemental Table S1). Both of these were 358assigned with sequence data from EMBL (L. latinasus: KM091595, L. laevis: AY843696). 359Lysapsus laevis would be the first record of this genus in the study area, but the identification of 360 Lysapsus populations only using short 16S eDNA sequences is questionable, especially when 361 considering the unclear taxonomy of the group in Bolivia. Nevertheless, based on their 362distribution and ecology all of the four known species of Lysapsus (L. boliviana, L. caraya, $L$. 363laevis, L. limellum) may occur at the site (De la Riva et al. 2000; Lavilla et al. 2004; Reichle 3642004a; b; Angulo 2008; Jansen et al. 2011; Frost 2016). They may have remained undetected 
365thus far simply because of their small size and rather inconspicuous advertisement call.

366Leptodactylus latinasus is another species possibly occurring in the area that had so far never 367been recorded (de Sá et al. 2014) and we cannot exclude the possibility that the corresponding 368sequence variant is actually an erroneous variant of one of the six local Leptodactylus species.

370not by eDNA (Fig. 2A, Supplemental Table S1). None of these species are strictly bound to 371ponds in the life stages occurring during our sampling: Dendropsophus arndti and D. salli, 372usually call from plants on the pond shores (Schulze et al. 2009) and have only sporadic contact 373with water. Leptodactylus fuscus and Pseudopaludicola sp. also do not enter the water but 374usually call from nearby muddy grounds or grasslands. We did not detect tadpoles of these 375species in the ponds: the tadpoles of these species develop during the rainy season which 376triggers reproduction, but our sampling slightly preceded the rainy season. Some of the other 377undetected species have terrestrial or quasi-terrestrial life histories: L. fuscus deposits eggs 378within foam nests in underground burrows at some distance from ponds and these are washed 379into nearby water bodies by floods that follow heavy rains (Heyer 1978; Lucas et al. 2008). 380Boana geographica was likely missed as a result of PCR bias: we could never recover it from 381 positive controls when DNA from other species was also present (Supplemental Fig. S2), 382although single-template PCR reactions worked. $H$. geographicus was also not detected by 383VAES, so it is possible that the species was not present during the survey. If we consider the 384specific life histories, the one-time eDNA survey only missed a single species 385(Sphaenorhynchus lacteus) in the area which was found calling from the water during the VAES 386(Fig. 2B, Supplemental Table S1). Regarding the whole local species pool (45 species in 10 387years), some of the species (10) may not be detectable by eDNA since they reproduce outside 388of water (e.g. Leptodactylus mystacinus), or are forest dwellers (e.g. Leptodactylus cf. didymus, 389Fig. 2D, Table S2). Overall, the results suggests that eDNA performed similarly well in detecting 
390species as VAES, but it was not successful to identify all species occurring at the specific 391ponds. Differences among individual ponds may result from the differential observational biases 392of eDNA and VAES approaches, none of which is providing a "true" list of species (hence the 393long-standing need to model species occupancy). eDNA methods seem to be a powerful tool for 394the detection of elusive life stages and less abundant species in tropical communities: with a 395single sampling eDNA detected more than half of the 45 species known to be present in the $396 a r e a$, and about $65 \%$ of the detectable species from the area (23 out of 35$)$.

398reproduced in the ponds. Repeating the sampling during the rainy season could have increased 399species detections by eDNA. The results show the importance of life history in the 400metabarcoding-based survey of tropical frogs and emphasize that sampling at multiple time 401points may be essential for more complete species pools also with eDNA (see 402Recommendations and technical remarks in the Supplemental information). Comprehensive 403and taxonomically sound sequence databases are essential for eDNA metabarcoding studies: 404we had a database that contained all 45 species that were ever recorded in the area. This 405database was essential for both initial primer development, and taxonomic assignments: indeed, 406both eDNA-recorded taxa that were not present on the complete local species list of the present 407study (Fig. 2, Supplemental Table S2) were identified in the EMBL-based assignment that 408followed the assignment with the custom local 165 database. The importance of sequence 409assignment databases is long recognized, with considerable efforts underway to establish them 410(Ratnasingham \& Hebert 2007; Coissac et al. 2016). There is an urgent need of further DNA 411sampling to create regional reference data banks, but only a few studies aim at completing DNA 412sampling of local anurofaunas in South America (e.g. Jansen et al. 2011; Guarnizo et al. 2015; 413Moraes et al. 2017). However, a preferably complete geographical and taxonomic coverage is 414necessary for continent-wide eDNA-based frog inventories. Increased DNA sampling will also 
415increase knowledge about actual distributions and taxonomy of Neotropical frogs (including 416cryptic lineages). This will improve IUCN evaluations, which currently clearly lack distributional 417information (Supplemental Table S1).

418 There was considerable variation in the species recorded with the spatial replicates of 419the eDNA samples, and this underlines that eDNA sampling should be replicated for a good 420representation of community composition. These samples may be pooled before DNA extraction 421 to optimize costs if site-level variation is not of interest. Interestingly, community structures 422across ponds inferred from both eDNA and VAES datasets where highly similar (Fig. 3). The 423eDNA data did not distinguish the communities from ponds T1 and T3, and these communities 424also grouped closely in the VAES results. Although the comparison of frog community structures 425among the assessed ponds may be confounded by the different sample sizes (with the eDNA 426ordination based on many spatial replicates and the VAES ordination on a single observation 427event per pond), and the eDNA ordinations are based on read-abundances in contrast to the 428VAES presence-absence ordinations, the correspondence of the results is still striking. Similar 429results were found in insect (Ji et al. 2013; Elbrecht et al. 2017) and plant communities 430(Niemeyer et al. 2017) where eDNA-based and morphology-based identifications result in 431similar conclusions about community structure, despite markedly different species lists. Our 432results provide further evidence that eDNA-based biodiversity surveys are highly sensitive to 433differences among ecological communities. These inferences are comparable to those derived 434with encounter-based observations and are informative about processes that underlay 435community assembly.

436 Although central to deciding on a method for biodiversity surveys, cost comparisons are 437not straightforward since they need to be based on expert knowledge both in VAES and eDNA. 438Cost comparisons were performed for single species eDNA detection (Huver et al. 2015; Davy 439et al. 2015; Smart et al. 2016), but we are not aware of frameworks suitable for eDNA 
440metabarcoding. Here the VAES cost estimation is informed by over a decade of field and 441integrative taxonomic work with tropical frogs (Jansen et al. 2007, 2016; Schulze et al. 2009; 442Brusquetti et al. 2014), while the eDNA part is only informed by a few years of eDNA 443biodiversity surveys (Bálint et al. 2016; Vörös et al. 2017). Such comparisons are urgently 444needed due to stakeholder demands in eDNA (e.g. governmental agencies, conservation 445NGOs, fisheries, etc.).

446 The two species richness scenarios we defined for cost comparisons (Fig. 4) shows that 447VAES costs become high in regions with high frog richness since they are a function of both the 448number of sites and the number of species. Biodiversity surveys with eDNA are not necessarily 449cheaper in low-richness regions since entry costs for the eDNA work are high: lab consumables 450and sequencing are costly. However, eDNA survey costs are not dependent on the local 451 biodiversity since metabarcoding can consider thousands of species simultaneously in a sample 452(Taberlet et al. 2012b). Consequently, eDNA costs are function of sample numbers, which 453influence the collection time spent on the field and consumables. eDNA metabarcoding 454operations are easily scaled up in a sense that hundreds of samples can be simultaneously 455processed (Ficetola et al. 2015).

456 Several aspects of our cost models are contentious. One issue is whether the relatively 457untrained VAES observers, or taxonomic experts perform the fieldwork, since taxonomic experts 458may identify many of the targeted frog species immediately on the field. Currently, most surveys 459of high-diversity areas are directly done by experts interested in the local fauna, but we argue 460that this will not work for continental - global biodiversity surveys simply because there are not 461enough taxonomic experts (Buyck 1999; Haas \& Häuser 2003). We also did not consider a 462scenario when VAES surveys are performed with automated recording devices (ARDs), and 463sounds are automatically identified by algorithms (see Recommendations and technical remarks 464in the Supplemental Information). The sound complexity in tropical environments currently 
465prohibits the use of automated sound identifications (Campos-Cerqueira \& Aide 2016). It is also 466difficult to compare fundamental infrastructure and training costs (i.e. the establishment of an 467 DNA laboratory versus the training of taxonomic experts). Discussions about cost models are 468timely since they will play major roles in devising much needed continental and global 469biodiversity surveys (Tittensor et al. 2014). 
$470 \quad$ Conclusions

471 eDNA seems to be suitable to standardized biodiversity surveys of frogs even in

472species-rich areas, but it may be overly costly for smaller studies in low-richness regions.

473Differences between eDNA and traditional surveys seem to result largely from different

474observational biases. Consideration of life histories promises to improve comprehensiveness of

475both types of surveys and thus also their correspondence. The eDNA data is certainly suitable

476to characterize not only community composition, but also the factors that shape communities:

477this gives an unprecedented opportunity to incorporate eDNA as a standard toolkit for

478community ecology and macroecology. Assessing community structure with eDNA-based

479community data foresees global biodiversity surveys and monitoring that will support both

480biodiversity research, and informed decisions on sustainable use of biological diversity. 


\section{Acknowledgements}

483 The authors thank Jenny Wertheimer for technical assistance during eDNA extraction, 484José Ribeiro for a helpful discussion on passive acoustic monitoring, and Simon Vitecek for 485helpfuls suggestions on the manuscript. MJ, AS and JLA thank the owners of Hacienda San 486Sebastián (family Werding) for their invitation to conduct herpetological surveys on their 487properties and for logistic support. TC was supported by the USGS Amphibian Research and 488Monitoring Initiative. MJ was supported by the Erika and Walter Datz-Stiftung, Bad Homburg v. 489d. H., equipment was sponsored by Globetrotter, Frankfurt. This research presents an outcome 490of the Centre for Translational Biodiversity Genomics (LOEWE-TBG) and was supported by the 491research funding programme "LOEWE - Landes-Offensive zur Entwicklung Wissenschaftlich4920̈konomischer Exzellenz" of Hesse's Ministry of Higher Education, Research, and the Arts. 


\section{$494 \quad$ References}

495Angulo A (2008) Lysapsus boliviana. The IUCN Red List of Threatened Species.

496Bailey LL, MacKenzie DI, Nichols JD (2014) Advances and applications of occupancy models.

497 Methods in ecology and evolution / British Ecological Society, 5, 1269-1279.

498Bálint M, Bahram M, Eren AM et al. (2016) Millions of reads, thousands of taxa: microbial

499 community structure and associations analyzed via marker genes. FEMS microbiology

500 reviews, 40, 686-700.

501Bálint M, Domisch S, Engelhardt CHM et al. (2011) Cryptic biodiversity loss linked to global 502 climate change. Nature climate change, 1, 313-318.

503Bálint M, Nowak C, Márton O et al. (2017) Input files for the comparison of visual-audio

504 encounter surveys and eDNA metabarcoding of species-rich tropical frog communities.

505 https://doi.org/10.6084/m9.figshare.5099842

506Barnosky AD, Matzke N, Tomiya S et al. (2011) Has the Earth's sixth mass extinction already

507 arrived? Nature, 471, 51-57.

508Bishop PJ, Angulo A, Lewis JP (2012) The amphibian extinction crisis-what will it take to put the 509 action into the amphibian conservation action plan? SAPI EN. S. Surveys.

510Bista I, Carvalho GR, Walsh K et al. (2017) Annual time-series analysis of aqueous eDNA

511 reveals ecologically relevant dynamics of lake ecosystem biodiversity. Nature

$512 \quad$ communications, 8, 14087.

513Bohmann K, Evans A, Gilbert M et al. (2014) Environmental DNA for wildlife biology and

514 biodiversity monitoring. Trends in ecology \& evolution, 29, 358-367.

515Boyer F, Mercier C, Bonin A et al. (2016) obitools: a unix-inspired software package for DNA

516 metabarcoding. Molecular ecology resources, 16, 176-182.

517Brusquetti F, Jansen M, Barrio-Amorós et al. (2014) Taxonomic review of Scinax 
518 fuscomarginatus (Lutz, 1925) and related species (Anura; Hylidae). Zoological journal of 519 the Linnean Society, 171, 783-821.

520Bush A, Sollmann R, Wilting A et al. (2017) Connecting Earth observation to high-throughput 521 biodiversity data. Nature Ecology \& Evolution, 1, 176.

522Butchart SHM, Walpole M, Collen B et al. (2010) Global biodiversity: indicators of recent 523 declines. Science, 328, 1164-1168.

524Buyck B (1999) Taxonomists are an endangered species in Europe. Nature, 401, 321.

525Caminer MA, Milá B, Jansen M et al. (2017) Systematics of the Dendropsophus leucophyllatus

526 species complex (Anura: Hylidae): Cryptic diversity and the description of two new species.

$527 \quad$ PloS one, 12, e0171785.

528Campos-Cerqueira M, Aide TM (2016) Improving distribution data of threatened species by

529 combining acoustic monitoring and occupancy modelling. Methods in ecology and evolution 530 / British Ecological Society, 7, 1340-1348.

531Castro AAJF, A A J, Martins FR, Tamashiro JY, Shepherd GJ (1999) How rich is the flora of

532 Brazilian Cerrados? Annals of the Missouri Botanical Garden. Missouri Botanical Garden,

$53386,192$.

534Clarke DA, York PH, Rasheed MA, Northfield TD (2017) Does biodiversity-ecosystem function

535 literature neglect tropical ecosystems? Trends in ecology \& evolution, 32, 320-323.

536Coissac E, Hollingsworth PM, Lavergne S, Taberlet P (2016) From barcodes to genomes:

537 extending the concept of DNA barcoding. Molecular ecology, 25, 1423-1428.

538Costello MJ, May RM, Stork NE (2013) Can we name Earth's species before they go extinct?

539 Science, 339, 413-416.

540Cristescu ME (2014) From barcoding single individuals to metabarcoding biological

541 communities: towards an integrative approach to the study of global biodiversity. Trends in

542 ecology \& evolution, 29, 566-571.

543Davy CM, Kidd AG, Wilson CC (2015) Development and validation of environmental DNA 
544 (eDNA) markers for detection of freshwater turtles. PloS one, 10, e0130965.

545De la Riva I, Köhler J, Lötters S, Reichle S (2000) Ten years of research on Bolivian

546 amphibians: updated checklist, distribution, taxonomic problems, literature and

547 iconography. Revista espanola de herpetologia, 14, 19-164.

548de Sá RO, Grant T, Camargo A et al. (2014) Systematics of the neotropical genus

549 Leptodactylus Fitzinger, 1826 (Anura: Leptodactylidae): phylogeny, the relevance of non-

550 molecular evidence, and species accounts. South american journal of herpetology /

551 Sociedade Brasileira de Herpetologia, 9, S1-S100.

552Duellman W, Pyles R (1983) Acoustic resource partitioning in anuran communities. Copeia, 1983,

$553 \quad 639-649$.

554Elbrecht V, Vamos EE, Meissner K, Aroviita J, Leese F (2017) Assessing strengths and

555 weaknesses of DNA metabarcoding-based macroinvertebrate identification for routine

556 stream monitoring. Methods in ecology and evolution / British Ecological Society, 8, 1265-

$557 \quad 1275$.

558Ferrão M, Colatreli O, de Fraga R et al. (2016) High species richness of Scinax treefrogs

559 (Hylidae) in a threatened Amazonian landscape revealed by an integrative approach. PloS

560 one, 11, e0165679.

561Ficetola, GF, Miaud C, Pompanon F, Taberlet P (2008) Species detection using environmental 562 DNA from water samples. Biology letters, 4, 423-425.

563Ficetola, GF, Miaud C, Pompanon F, Taberlet P (2008) Species detection using environmental 564 DNA from water samples. Biology letters, 4, 423-425.

565Fiske I, Chandler R, Others (2011) unmarked: An R package for fitting hierarchical models of 566 wildlife occurrence and abundance. Journal of statistical software, 43, 1-23.

567Fouquet A, Gilles A, Vences M et al. (2007) Underestimation of species richness in neotropical 568 frogs revealed by mtDNA analyses. PloS one, 2, e1109.

569Frost DR (2016) Amphibian Species of the World: an Online Reference. Version 6.0. 
570Gehara M, Canedo C, Haddad CFB, Vences M (2013) From widespread to microendemic:

571 molecular and acoustic analyses show that Ischnocnema guentheri (Amphibia:

572 Brachycephalidae) is endemic to Rio de Janeiro, Brazil. Conservation genetics , 14, 973-

573982.

574Gehara M, Crawford AJ, Orrico VGD et al. (2014) High levels of diversity uncovered in a

575 widespread nominal taxon: continental phylogeography of the Neotropical tree frog

576 Dendropsophus minutus. PloS one, 9, e103958.

577Goldberg, CS, Pilliod DS, Arkle RS, Waits LP (2011) Molecular detection of vertebrates in

578 stream water: A demonstration using Rocky Mountain Tailed Frogs and Idaho Giant

579 Salamanders. Plos One, 6, e22746.

580Guarnizo CE, Paz A, Muñoz-Ortiz A, et al. (2015) DNA barcoding survey of anurans across the

581 eastern Cordillera of Colombia and the impact of the Andes on cryptic diversity. PLoS one,

$582 \quad 10, \mathrm{e} 0127312$.

583Haas F, Häuser CL (2003) Taxonomists: an endangered species? In: Success stories in

584 implementation of the programmes of work on dry and sub-humid lands and the global

585 taxonomy initiative, p. 87. Montreal: Secretariat of the Convention on Biological Diversity

586Haddad, CFB, Prado CPA (2005); Reproductive modes in frogs and their unexpected diversity

587 in the Atlantic Forest of Brazil. BioScience, 55, 207-217.

588Henry P-Y, Lengyel S, Nowicki P et al. (2008) Integrating ongoing biodiversity monitoring:

589 potential benefits and methods. Biodiversity and conservation, 17, 3357-3382.

590Heyer WR (1978) Systematics of the fuscus group of the frog genus Leptodactylus (Amphibia,

591 Leptodactylidae). Natural History Museum of Los Angeles County.

592Hinlo R, Gleeson D, Lintermans M, Furlan E (2017) Methods to maximise recovery of

593 environmental DNA from water samples. PloS one, 12, e0179251.

594Hui FKC, Taskinen S, Pledger S, Foster SD, Warton DI (2015) Model-based approaches to

595 unconstrained ordination. Methods in ecology and evolution / British Ecological Society, 6 , 
$596 \quad 399-411$.

597Huver JR, Koprivnikar J, Johnson PTJ, Whyard S (2015) Development and application of an

598 eDNA method to detect and quantify a pathogenic parasite in aquatic ecosystems.

599 Ecological applications: a publication of the Ecological Society of America, 25, 991-1002.

600Jansen M (2009) Measuring temporal variation in calling intensity of a frog chorus with a data

601 logging sound level meter: results from a pilot study in Bolivia. Herpetology notes, 2, 143-

602149.

603Jansen M, Álvarez LG, Köhler G (2007) New species of Hydrolaetare (Anura, Leptodactylidae)

604 from Bolivia with some notes on Its natural history. Journal of Herpetology, 41, 724-732.

605Jansen M, Bloch R, Schulze A, Pfenninger M (2011) Integrative inventory of Bolivia's lowland

606 anurans reveals hidden diversity. Zoologica scripta, 40, 567-583.

607Jansen M, Plath M, Brusquetti F, Ryan MJ (2016) Asymmetric frequency shift in advertisement

608 calls of sympatric frogs. Amphibia-reptilia: publication of the Societas Europaea

609 Herpetologica, 37, 137-152.

610Jerde CL, Mahon AR, Chadderton WL, Lodge DM (2011) “Sight-unseen” detection of rare

611 aquatic species using environmental DNA. Conservation letters, 4, 150-157.

612Ji Y, Ashton L, Pedley SM et al. (2013) Reliable, verifiable and efficient monitoring of

613 biodiversity via metabarcoding. Ecology letters, 16, 1245-1257.

614Jungfer K-H, Reichle S, Piskurek O (2010) Description of a new cryptic southwestern

615 Amazonian species of leaf-gluing treefrog, genus Dendropsophus (Amphibia: Anura:

616 Hylidae). Salamandra, 46, 204-213.

617Kozarewa I, Turner DJ (2011) 96-plex molecular barcoding for the Illumina Genome Analyzer.

618 In: High-Throughput Next Generation Sequencing (eds Kwon YM, Ricke CR), pp. 279-298.

619 Humana Press, Totowa, NJ.

620Lavilla E, Reichle S, Lajmanovich R, Faivovich, Julian (2004) Lysapsus limellum. The IUCN

621 Red List of Threatened Species. 
622Lees AC, Pimm SL (2015) Species, extinct before we know them? Current biology: CB, 25, 623 R177-80.

624Lopes CM, Sasso T, Valentini A et al. (2016) eDNA metabarcoding: a promising method for 625 anuran surveys in highly diverse tropical forests. Molecular ecology resources, 17, 904626914.

627Lucas EM, Brasileiro CA, Oyamaguchi HM, Martins M (2008) The reproductive ecology of 628 Leptodactylus fuscus (Anura, Leptodactylidae): new data from natural temporary ponds in 629 the Brazilian Cerrado and a review throughout its distribution. Journal of natural history, $\mathbf{4 2 ,}$ $630 \quad 2305-2320$.

631MacKenzie DI, Nichols JD, Lachman GB et al. (2002) Estimating site occupancy rates when 632 detection probabilities are less than one. Ecology, 83, 2248-2255.

633Miles L, Newton AC, DeFries RS et al. (2006) A global overview of the conservation status of 634 tropical dry forests. Journal of biogeography, 33, 491-505.

635Miller DA, Nichols JD, McClintock BT et al. (2011) Improving occupancy estimation when two 636 types of observational error occur: non-detection and species misidentification. Ecology, 92 , 637 1422-1428.

638Miya M, Sato Y, Fukunaga T et al. (2015) MiFish, a set of universal PCR primers for 639 metabarcoding environmental DNA from fishes: detection of more than 230 subtropical 640 marine species. Royal Society open science, 2, 150088.

641Moraes LJCL, Almeida AP, Fraga R et al. (2017) Integrative overview of the herpetofauna from 642 Serra da Mocidade, a granitic mountain range in Northern Brazil . ZooKeys, 715, 103-159. 643Møller AP (2010) When climate change affects where birds sing. Behavioral ecology: official 644 journal of the International Society for Behavioral Ecology, 22, 212-217. 645Niemeyer B, Epp LS, Stoof-Leichsenring KR, Pestryakova LA, Herzschuh U (2017) A 646 comparison of sedimentary DNA and pollen from lake sediments in recording vegetation 647 composition at the Siberian treeline. Molecular ecology resources, 17, e46-e62. 
648Ortega-Andrade HM, Rojas-Soto OR, Valencia JH et al. (2015) Insights from integrative 649 systematics reveal cryptic diversity in Pristimantis frogs (Anura: Craugastoridae) from the $650 \quad$ Upper Amazon Basin. PloS one, 10, e0143392.

651Pauls SU, Nowak C, Bálint M, Pfenninger M (2013) The impact of global climate change on 652 genetic diversity within populations and species. Molecular ecology, 22, 925-946.

653Pedersen MW, Overballe-Petersen S, Ermini L et al. (2015) Ancient and modern environmental 654 DNA. Philosophical transactions of the Royal Society of London. Series B, Biological 655 sciences, 370, 20130383.

656Peres-Neto PR, Jackson DA (2001) How well do multivariate data sets match? The advantages 657 of a pProcrustean superimposition approach over the Mantel test. Oecologia, 129, 169658178.

659Petitot M, Manceau N, Geniez P, Besnard A (2014) Optimizing occupancy surveys by 660 maximizing detection probability: application to amphibian monitoring in the Mediterranean 661 region. Ecology and evolution, 4, 3538-3549.

662Pfenninger M, Schwenk K (2007) Cryptic animal species are homogeneously distributed among 663 taxa and biogeographical regions. BMC evolutionary biology, 7, 121.

664Pimm SL, Jenkins CN, Abell R et al. (2014) The biodiversity of species and their rates of 665 extinction, distribution, and protection. Science, 344, 1246752.

666Power MJ, Whitney BS, Mayle FE et al. (2016) Fire, climate and vegetation linkages in the 667 Bolivian Chiquitano seasonally dry tropical forest. Philosophical transactions of the Royal 668 Society of London. Series B, Biological sciences, 371, 20150165.

669Ratnasingham S, Hebert PDN (2007) BARCODING: bold: The barcode of life data system 670 (http://www.barcodinglife.org). Molecular ecology notes, 7, 355-364.

671R Core Team (2017) R: A Language and Environment for Statistical Computing.

672Rees HC, Maddison BC, Middleditch DJ et al. (2014) The detection of aquatic animal species 673 using environmental DNA - a review of eDNA as a survey tool in ecology. Journal of applied 
675Reichle S (2004a) Lysapsus laevis. The IUCN Red List of Threatened Species.

676Reichle S (2004b) Lysapsus caraya. The IUCN Red List of Threatened Species.

677Schmeller DS, Böhm M, Arvanitidis C et al. (2017) Building capacity in biodiversity monitoring at 678 the global scale. Biodiversity and conservation, 26, 2765-2790.

679Schulze A, Jansen M, Köhler G (2009) Diversity and ecology of anuran communities in San 680 Sebastián (Chiquitano region, Bolivia). Salamandra, 45, 75-90.

681Schulze A, Jansen M, Köhler G (2015) Tadpole diversity of Bolivia's lowland anuran 682 communities: molecular identification, morphological characterisation, and ecological 683 assignment. Zootaxa, 4016, 1-111.

684Shaw JLA, Clarke LJ, Wedderburn SD, et al. (2016) Comparison of environmental DNA 685 metabarcoding and conventional fish survey methods in a river system. Biological 686 Conservation, 197, 131-138.

687Smart AS, Weeks AR, van Rooyen AR et al. (2016) Assessing the cost-efficiency of 688 environmental DNA sampling. Methods in Ecology and Evolution, 7, 1291-1298.

689Spens J, Evans AR, Halfmaerten D, et al. (2017) Comparison of capture and storage methods 690 for aqueous macrobial eDNA using an optimized extraction protocol: advantage of enclosed 691 filter. Methods in Ecology and Evolution, 8, 635-645.

692Strand DA, Jussila J, Johnsen SI et al. (2014) Detection of crayfish plague spores in large 693 freshwater systems. The Journal of applied ecology, 51, 544-553.

694Stroud JT, Feeley KJ (2017) Neglect of the Tropics Is Widespread in Ecology and Evolution: A 695 Comment on Clarke et al. Trends in ecology \& evolution, 32, 626-628.

696Stuart SN, Chanson JS, Cox NA et al. (2004) Status and trends of amphibian declines and 697 extinctions worldwide. Science, 306, 1783-1786.

698Taberlet P, Coissac E, Hajibabaei M, Rieseberg LH (2012a) Environmental DNA. Molecular 699 ecology, 21, 1789-1793. 
700Taberlet P, Coissac E, Pompanon F, Brochmann C, Willerslev E (2012b) Towards next-

701 generation biodiversity assessment using DNA metabarcoding. Molecular ecology, 21,

$702 \quad 2045-2050$.

703Thomsen, PF, Kielgast J, Iversen LL et al. (2012a) Monitoring endangered freshwater

704 biodiversity using environmental DNA. Molecular Ecology, 21, 2565-2573.

705Thomsen PF, Kielgast J, Iversen LL et al. (2012b) Detection of a diverse marine fish fauna

706 using environmental DNA from seawater samples. PloS one, 7, e41732. Thomsen PF,

707 Willerslev E (2015) Environmental DNA - An emerging tool in conservation for monitoring

708 past and present biodiversity. Biological conservation, 183, 4-18.

709Tittensor DP, Walpole M, Hill SLL et al. (2014) A mid-term analysis of progress toward

710 international biodiversity targets. Science, 346, 241-244.

711UNEP (2016) The strategic plan for biodiversity 2011-2020, the Aichi biodiversity targets and

712 NBSAPs. In: Sourcebook of Opportunities for Enhancing Cooperation among the

713 Biodiversity-Related Conventions at National and Regional Levels, pp. 108-135.

714Valentini A, Taberlet P, Miaud C et al. (2016) Next-generation monitoring of aquatic biodiversity

715 using environmental DNA metabarcoding. Molecular ecology, 25, 929-942.

716Vörös J, Márton O, Schmidt BR, Gál JT, Jelić D (2017) Surveying Europe’s only cave-dwelling

717 chordate species (Proteus anguinus) using environmental DNA. PloS one, 12, e0170945.

718Wang Y, Naumann U, Wright ST, Warton DI (2012) mvabund- an Rpackage for model-based

719 analysis of multivariate abundance data. Methods in ecology and evolution / British

720 Ecological Society, 3, 471-474.

721Wells KD (2010) The ecology and behavior of amphibians. University of Chicago Press.

722Whittaker K, Koo MS, Wake DB, Vredenburg VT (2013) Global declines of amphibians. In:

723 Encyclopedia of Biodiversity (Second Edition) (ed Levin SA), pp. 691-699. Academic

724 Press, Waltham.

725Wilson DM, Bart J (1985) Reliability of singing bird surveys: effects of song phenology during 
726 the breeding season. The Condor, 87, 69-73.

727Wittwer C, Stoll S, Cocchiararo B, Strand D, Vrålstad T, Nowak C, Thines M (2017) eDNA-

728 based crayfish plague monitoring is superior to conventional trap-based assessments in

729 year-round detection probability. Hydrobiologia (pending minor revision).

730Yamamoto S, Masuda R, Sato Y et al. (2017) Environmental DNA metabarcoding reveals local

731 fish communities in a species-rich coastal sea. Scientific reports, 7, 40368.

732Zimmerman BL (1994) Audio strip transects. In: Measuring and monitoring biological

733 biodiversity. Standard methods for amphibians (eds Heyer WR, Donnelly MA, McDiarmid

734 RW, Hayek LC, Foster MS), pp. 99-108. Smithsonian Institution Press, Washington DC.

735

736

737 
bioRxiv preprint doi: https://doi.org/10.1101/176065; this version posted July 13, 2018. The copyright holder for this preprint (which was not certified by peer review) is the author/funder, who has granted bioRxiv a license to display the preprint in perpetuity. It is made available under aCC-BY-ND 4.0 International license.

738

739 Data accessibility

740 DNA sequences: EMBL accession PRJEB22113

741 Cost model parameters and calculations: FigShare,

742https://doi.org/10.6084/m9.figshare.5099842.v5

743 Input data for statistical analyses: FigShare,

744https://doi.org/10.6084/m9.figshare.5099842.v5.

745 R-script for bioinformatic filtering and statistical analyses:

746https://doi.org/10.5281/zenodo.1294092

747 


\section{$748 \quad$ Author contributions}

749 M.B., M.J., C.N., C.W. designed research; J.L.A., M.B., M.J., O.M., A.S., C.W., B.C.

750performed research; B.C., T.C., C.N., S.U.P. contributed reagents or analytic tools; M.B., M.J.

751analysed data; M.B., T.C., M.J., O.M., C.N., S.U.P., wrote the manuscript.

752 


\section{Tables}

\section{Table 1.}

755 Numbers of detected species by method per pond (VAES = Visual-audio encounter

756surveys. Reduced VAES = only considering species that were in contact with water during

757survey).

\begin{tabular}{ccccc}
\hline Pond & eDNA & VAES & Reduced VAES & Tadpole survey \\
T1 & 10 & 8 & 6 & 4 \\
T2 & 7 & 4 & 4 & 3 \\
T3 & 3 & 7 & 3 & 0 \\
T4 & 9 & 15 & 13 & 1 \\
T5 & 13 & 18 & 14 & 1 \\
\hline
\end{tabular}

$75 \overline{8}$ 


\section{${ }_{759}$ Figures}

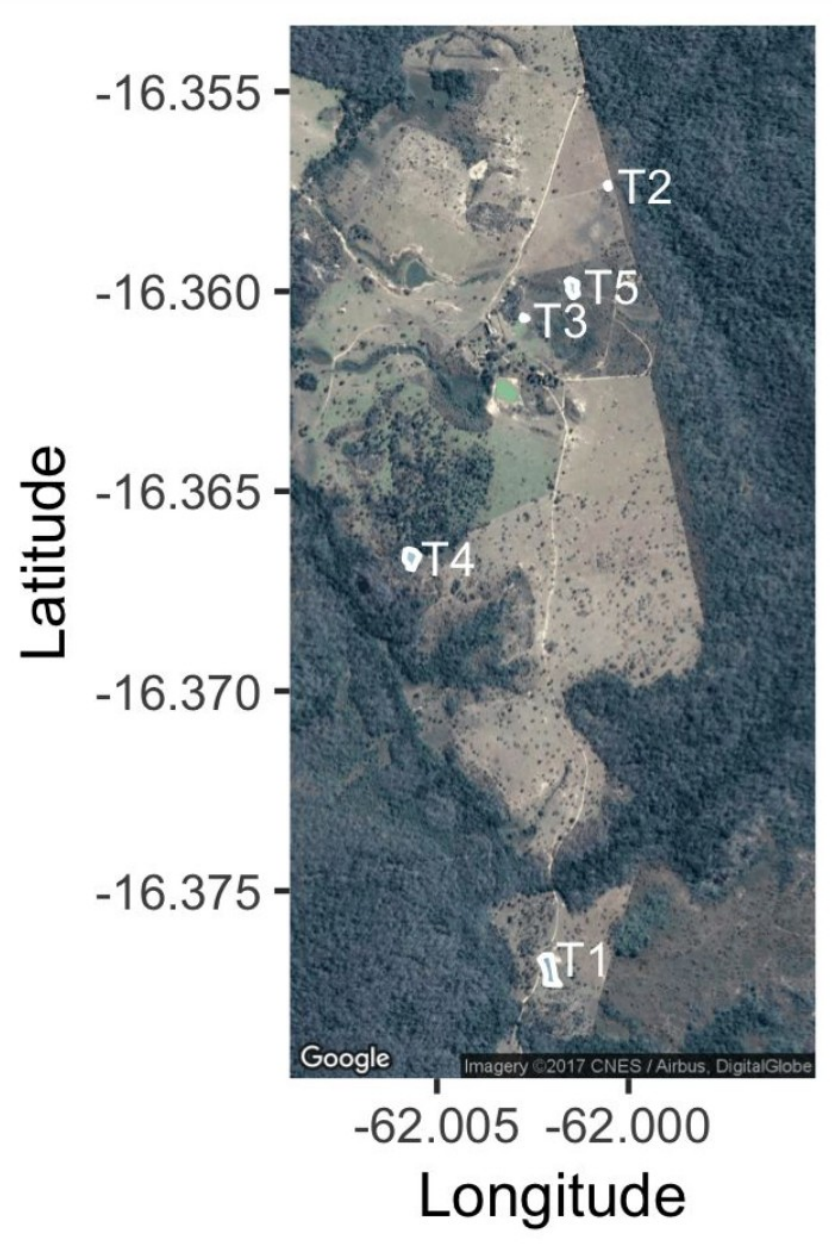

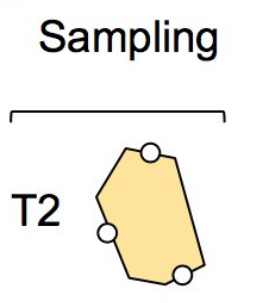

Filters, preservation,

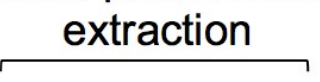

T5

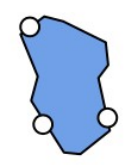

T3

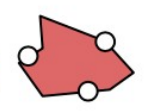

T4

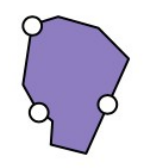

T1
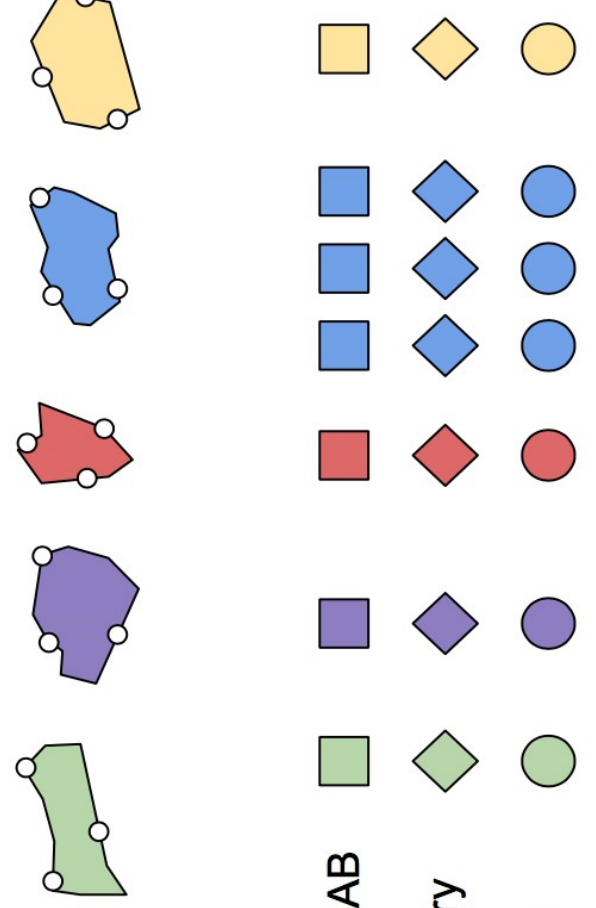

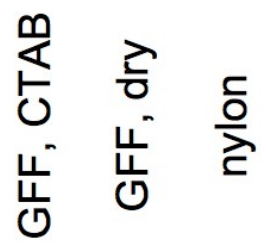

\section{Fig. 1.}

762 Sampled ponds, sampling replication, and filtration - filter preservation strategy. GFF -

763glass-fiber filter, $2 \mu \mathrm{m}$; nylon - nylon filter, $0.2 \mu \mathrm{m}$. Each sample (three per pond, marked with

764small circles) were processed with each three filtration strategies. Multiple samples of pond T5

765were three times processed with each filtration strategy. 
A

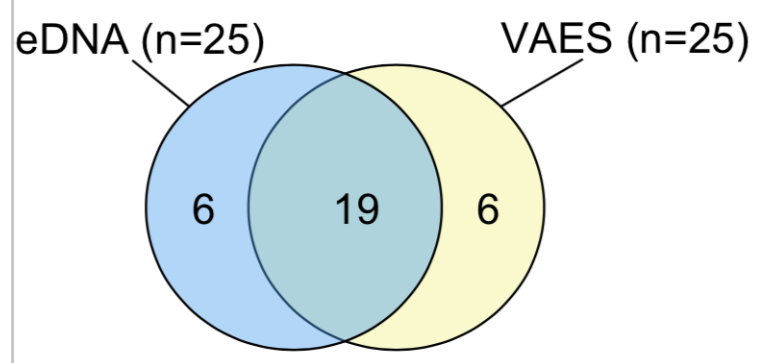

C

768

local species pool

$(n=45)$

B

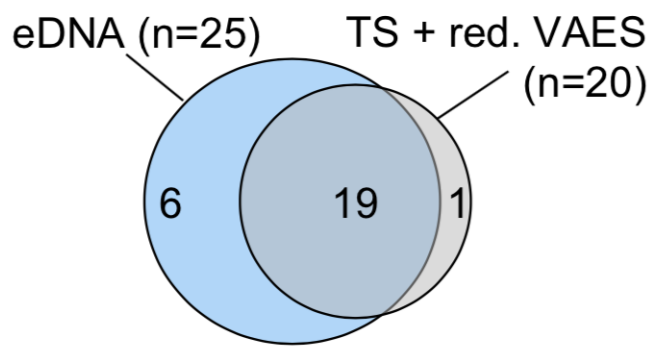

D

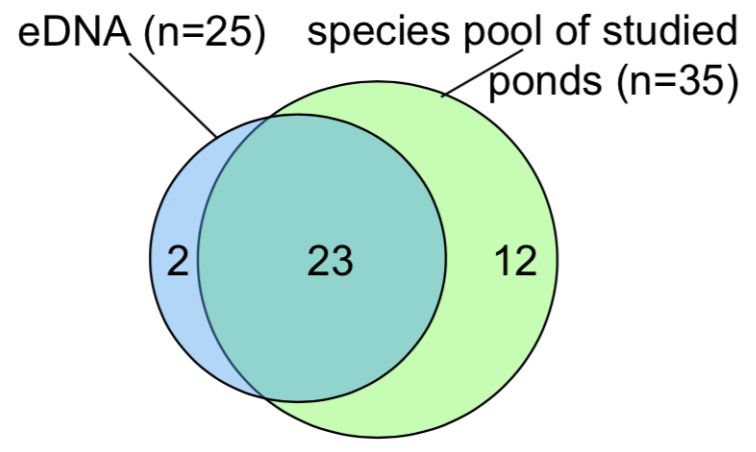

769

Fig. 2.

770 Comparison of species lists generated by eDNA (blue) and A) visual and audio

771encounter surveys (VAES, yellow), B) tadpole survey (TS) plus reduced VAES - only species 772with high eDNA detectability in ponds (see text for details; grey), C) complete local species pool 773(red), and D) species pool of studied ponds based on long-term monitoring (green).

774

775

776 


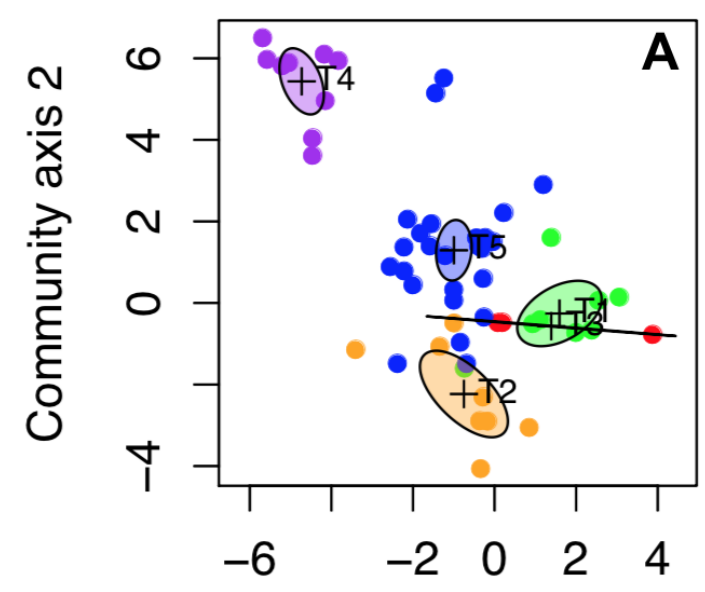

Community axis 1

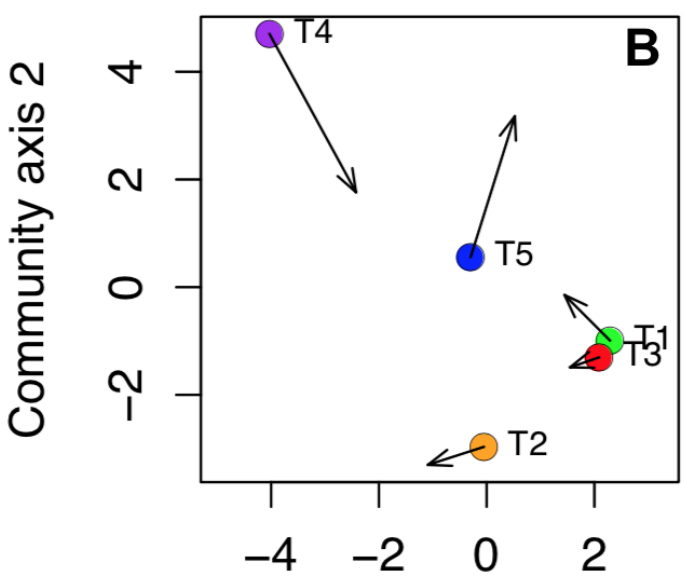

777

Community axis 1

$778 \quad$ Fig. 3.

779Comparison of ecological signal between visual and audio encounter surveys (VAES) and

780eDNA metabarcoding surveys. A - Latent variable model ordination of the pond samples

781 according to the read numbers of species. Water samples from each pond were taken at three

782locations. For ponds T1-T4, three samples at each location were filtered through two GFF (A,B), 783and one nylon filter $(C)$, resulting in nine samples per pond. For pond T5, each filtration was 784done three times. Not all samples contained reads after the bioinformatic quality filtering and 785these samples are not shown on the ordination (see e.g. T3 - red). The ellipses represent $95 \%$ 786 confidence intervals for the standard errors of the pond centroids (marked with +). B - Non- 
bioRxiv preprint doi: https://doi.org/10.1101/176065; this version posted July 13, 2018. The copyright holder for this preprint (which was not certified by peer review) is the author/funder, who has granted bioRxiv a license to display the preprint in perpetuity. It is made available under aCC-BY-ND 4.0 International license.

787metric multidimensional scaling plot of the five ponds (Jaccard distance), according to VAES 788species presence-absences. The arrows represent the Procrustes rotation of the VAES pond 789ordination and they target the group centroids of the latent variable model ordination. 


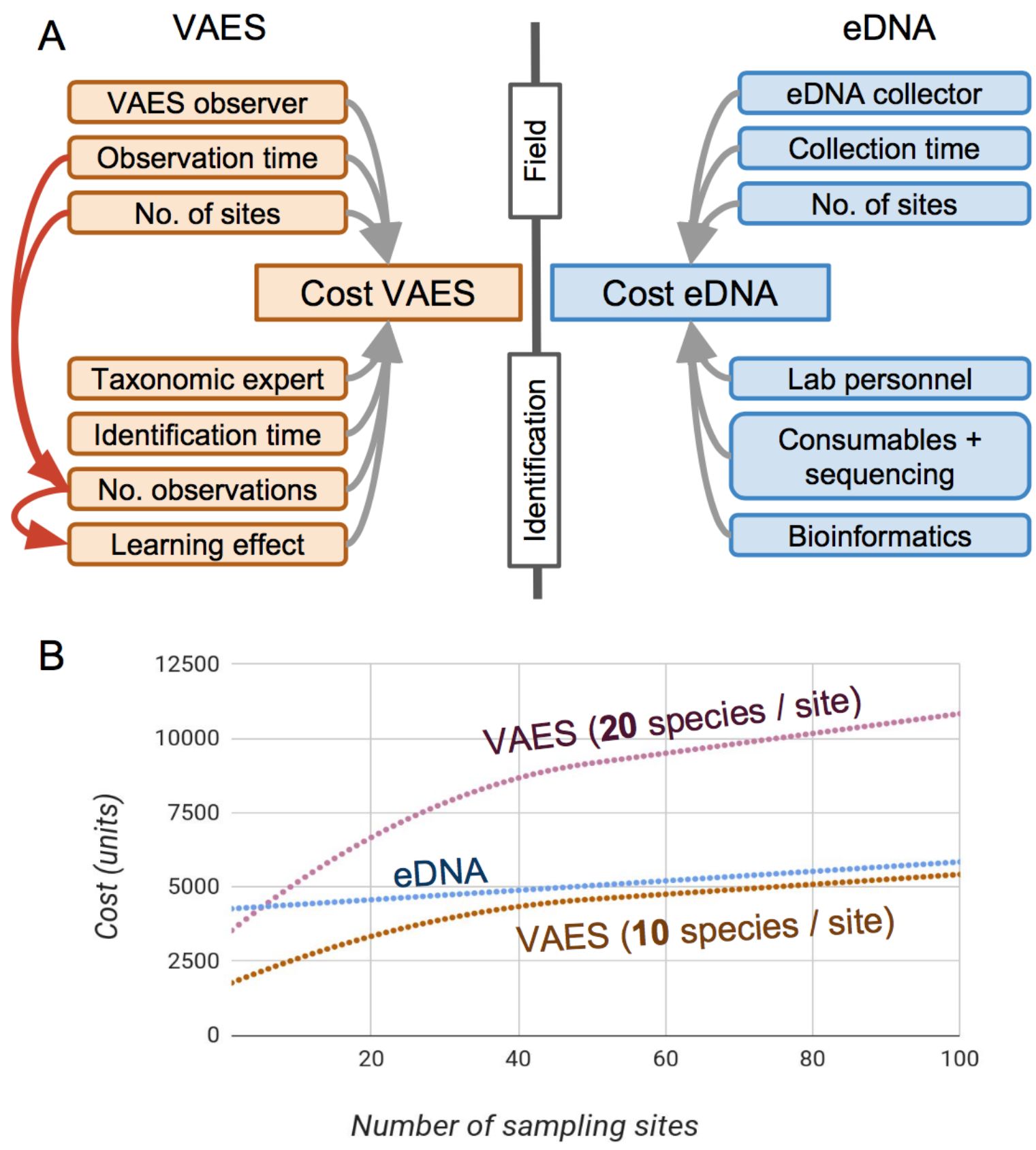

791 Fig. 4.

792 Cost comparisons between visual and audio encounter surveys (VAES) and eDNA 793metabarcoding surveys. A - Schematic overview of the visual and audio encounter survey 794(VAES) and eDNA cost models. Model parameters and calculations are accessible through 795FigShare (Balint_et_al_survey_cost_calculations.xlsx, 
bioRxiv preprint doi: https://doi.org/10.1101/176065; this version posted July 13, 2018. The copyright holder for this preprint (which was not certified by peer review) is the author/funder, who has granted bioRxiv a license to display the preprint in perpetuity. It is made available under aCC-BY-ND 4.0 International license.

796https://doi.org/10.6084/m9.figshare.5099842.v5). B - Cost comparisons of frog diversity surveys

797with eDNA, and two VAES scenarios (a low local species richness scenario - 10 species per

798site, and a medium-high species richness scenario - 20 species per site). 